University of Louisville

ThinkIR: The University of Louisville's Institutional Repository

\title{
Vonnegut's composite work : the importance of illustration in Breakfast of champions.
}

Blake Schreiner

University of Louisville

Follow this and additional works at: https://ir.library.louisville.edu/honors

Part of the Literature in English, North America Commons

\section{Recommended Citation}

Schreiner, Blake, "Vonnegut's composite work : the importance of illustration in Breakfast of champions." (2017). College of Arts \& Sciences Senior Honors Theses. Paper 142.

http://doi.org/10.18297/honors/142

This Senior Honors Thesis is brought to you for free and open access by the College of Arts \& Sciences at ThinkIR: The University of Louisville's Institutional Repository. It has been accepted for inclusion in College of Arts \& Sciences Senior Honors Theses by an authorized administrator of ThinkIR: The University of Louisville's Institutional Repository. This title appears here courtesy of the author, who has retained all other copyrights. For more information, please contact thinkir@louisville.edu. 


\section{Vonnegut's Composite Work:}

\section{The Importance of Illustration in Breakfast of Champions}

By

Blake Schreiner

Submitted in partial fulfillment of the requirements

for Graduation summa cum laude

and

for Graduation with Honors from the Department of English

University of Louisville

Louisville, KY

May 2017 


\section{TABLE OF CONTENTS}

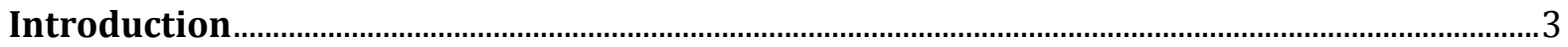

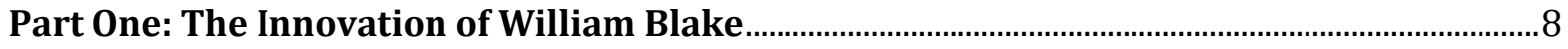

Part Two: Reconsidering Breakfast of Champions ................................................................................ 15

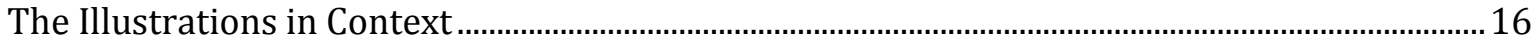

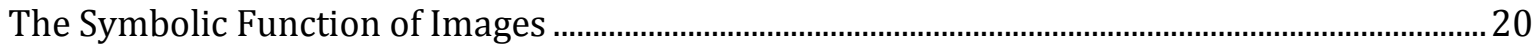

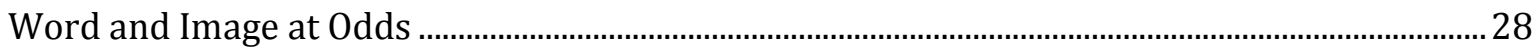

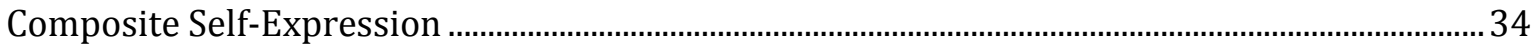

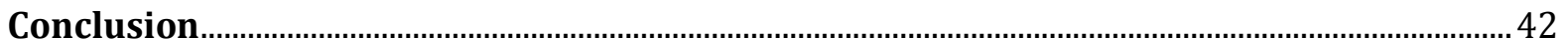




\section{Introduction}

Despite his prominence in the canon of postmodern American literature, Kurt Vonnegut remains a highly controversial figure in literary criticism. What some appreciate as creativity and literary innovation, others dismiss as self-indulgence and petty nihilism. In either case, now almost fifty years since Vonnegut reached the height of his literary success, his name has become synonymous with a checklist of postmodern tropes, making it all too easy to dismiss the nuances of his creative sophistication. Like a new Charles Dickens, Vonnegut has become the author that every high school student ceremoniously reads then immediately learns to underestimate. While Vonnegut is certainly no longer the groundbreaking voice of a generation, to assume that his writing is wholly predictable is wildly unfair to some of the innovative works found in his canon. One such treasure-which is often hastily labeled as one more rambling about the absurdity of life-deserves more credit, not only in the scope of postmodern fiction but in the history of English publication as well.

At the apex of Vonnegut's career sits his seventh novel, Breakfast of Champions, Or Goodbye Blue Monday (1973). Ranking among the more controversial of Vonnegut's total fourteen novels, it has been in many ways denied due critical consideration as a multidimensional artistic product. In truth, it is a difficult novel to approach, or to place within the context of Vonnegut's other writings, given that it was born out of the beginning of decline in the author's professional life. Having triumphantly completed SlaughterhouseFive, his mid-career masterpiece, Vonnegut understandably found himself at a crossroads of fulfillment and depression:

Well I felt after I finished Slaughterhouse-Five that I didn't have to write at all anymore if I didn't want to. It was the end of some sort of career. . . . So I had 
a shutting-off feeling, you know, that I had done what I was supposed to do and everything was $\mathrm{OK}$. And that was the end of it. I could figure out my missions for myself after that. ${ }^{1}$

In his personal life, the three years following the publication of Slaughterhouse-Five in 1969 included a divorce, a lonely move to New York City, and severe depression. ${ }^{2}$ These struggles linger barely beneath the surface of his seventh novel. Revolving around the miserable writing career of a character named Kilgore Trout (a not-so-subtle caricature of Vonnegut himself), Breakfast of Champions' predictable cynicism is compounded by a hyper-selfawareness of the fragile rise to success and the paranoia of an impending fall.

Structurally, Breakfast of Champions is a jarring successor to the tight, centralized narrative of Slaughterhouse-Five. Constructed primarily from material that was removed from early Slaughterhouse drafts, Breakfast appears to lack narrative focus, opting instead for a strong dose of self-redefinition. As the narrator confesses near the novel's climax:

Once I realized what was making America such a dangerous, unhappy nation of people who had nothing to do with real life, I resolved to shun storytelling. I would write about life. Every person would be exactly as important as any other. All facts would be given equal weightiness. Nothing would be left out. Let others bring order to chaos. I would bring chaos to order, instead, which I think I have done. . . . It is hard to adapt to chaos, but it can be done. I am living proof of that: It can be done. ${ }^{3}$

"Chaos" is an apt description for both the style and narrative content of this novel, which is formed from a collection of disjointed cultural criticisms, inconsequential tangents, and a series of haphazard events. Moreover, the heavy handed narrative voice of Breakfast is tricky because it intently pretends to be a version of the real Vonnegut, aware of its role in

\footnotetext{
${ }^{1}$ Kurt Vonnegut and William Rodney Allen, Conversations with Kurt Vonnegut (Jackson: University of Mississippi Press, 1988), 107.

${ }^{2}$ William Rodney Allen, Understanding Kurt Vonnegut (Columbia: University of South Carolina Press, 1991), 102.

${ }^{3}$ Kurt Vonnegut, Breakfast of Champions, or Goodbye Blue Monday, (New York: Dell Publishing, 1973), 210.
} 
fabricating the novel's characters and ultimately placing itself as a participant in the events of the novel's conclusion. These irregularities — not to mention the parody and nihilism they barely conceal—have led some critics to denounce, or give only cursory treatment to, this novel and the complexities it contains.

In popular reviews, Breakfast was crucified for its overbearing satirical voice. One particularly violent critic denounced its "gratuitous digressions," its "cretinous philosophizing," its "self-indulgence and its facile fatalism," concluding with the summation: "Manure, of course. Pretentious, hypocritical manure." ${ }^{4}$ In the realm of scholarly criticism, Breakfast fared somewhat better, and rightfully so. Robert Merrill has defended the novel as a highly deliberate exploration of hypocrisy, not a novel of facile fatalism, but "a novel about facile fatalism ... in [which] Vonnegut turns an extremely cold eye on his own artistic practices and philosophical assumptions." ${ }^{5}$ Other critical readers have shared Merrill's respect, treating the novel as a worthy piece in Vonnegut's philosophic puzzle. Popular themes to explore have included: the sophisticated layering of artistic personas (from Vonnegut himself to the fictional narrator, Philboyd Studge, to the novel's protagonist, Kilgore Trout $) ;{ }^{6}$ questions of existential struggle and suicide ${ }^{7}$ and the novel's place in the evolution of postmodern narrative structures. ${ }^{8}$ Regardless of value judgments as to the

\footnotetext{
${ }^{4}$ Peter S. Prescott, "Nothing Sacred [Review of Breakfast of Champions]," in Critical Essays on Kurt Vonnegut, ed. Robert Merrill (Boston: G. K. Hall \& Co., 1990), 40.

${ }^{5}$ Robert Merrill, "Vonnegut's Breakfast of Champions: The Conversion of Heliogabalus," in Critical Essays on Kurt Vonnegut, ed. Robert Merrill (Boston: G. K. Hall \& Co., 1990), 153.

${ }^{6}$ Charles Berryman, "Vonnegut's Comic Persona in Breakfast of Champions," in Critical Essays on Kurt Vonnegut, ed. Robert Merrill (Boston: G. K. Hall \& Co., 1990), 162.

${ }^{7}$ Deanna Rodriguez, "The Absurdity of Suicide: The Existential Struggle Explored by Vonnegut in Breakfast of Champions," New Academia: An International Journal of English Language Literature and Literary Theory 2, no. 4 (2013): 1-4.

8 Peter B. Messent, "Breakfast of Champions: The Direction of Kurt Vonnegut's Fiction," Journal of American Studies 8, (1974): 101-114.
} 
likeability of the novel, at least some critics have identified it as a sophisticated stepping stone in Vonnegut's journey as a creative writer.

As thorough as these critics have been in giving fair treatment to what is obviously more than just "hypocritical manure," they have almost entirely eclipsed the novel's most distinctive feature - its over one-hundred illustrations, sketched in the author's own hand. Not only was large scale self-illustration unprecedented in Vonnegut's published career, it is a rarity in modern and post-modern fiction in general. The drawings are conspicuous yet confounding, mostly crude sketches of common objects - a chicken, an apple, several tombstones, etc. - and the incredibly brief scholarly consensus is that they serve merely to scrutinize the unflattering banality of American visual culture. Such a one-dimensional interpretation is wholly unsatisfying, particularly given the drawings' prominence-both visually and stylistically — throughout the novel. The question therefore remains: What to make of this bizarre, pessimistic, illustrated text?

Much of the critical oversight regarding the function of graphic content in Breakfast of Champions may be attributed to the habit of examining the text in isolation - the drawings are conspicuous enough, and the text so self-aware, that it is tempting to examine their relationship in a vacuum. In many ways, Breakfast is indeed an isolated production since it occupies a largely unprecedented genre of multimedia literature. True, plenty of authors throughout history have dabbled (or, for that matter, excelled) in the graphic arts. Just as many, if not more, great literary works are accompanied by illustrations. However, publications that are written, illustrated, and conceived as a multimedia whole by a single author are few and far between. That being said, Breakfast of Champions does not, of course, 
exist in a vacuum, and a thorough reconsideration of its illustrations should look outward to the larger framework of multimedia publication.

In this context, the most helpful and feasible predecessor - though I use the word in its broadest sense-is William Blake, the first man to bring such holistic publications into being. Of course, as components of distinct literary movements, as perpetuators of creative philosophies, and even as physical products, the illuminated manuscripts of William Blake and Vonnegut's Breakfast of Champions bear little, if any, resemblance. However, enough fundamental similarities exist in the way the works are conceived of, and function as, interdisciplinary productions that a brief consideration of Blake's practice sheds more light on Breakfast of Champions, both in terms of how it functions in its own right and how it marks another innovative milestone in the history of print publication.

While many critics have cited Vonnegut's illustrations in their capacity as descriptive additions, and therefore subordinate entries, to the narrative content of the text, I contend that Breakfast of Champions' graphic components are weighted equally to the text. Therefore, a full appreciation of the novel's narrative potential can only be realized if the illustrations are considered as collaborative partners with Vonnegut's written word. This unique publication does not simply juxtapose image and text, as so many scholars have assumed, rather it fuses them into a single creative entity, in which lies the deeper significance of the novel. As such, Breakfast of Champions' graphic quality must be considered in greater detail, and in reference to the greater history and theories of multimedia publication. 


\section{Part One: The Innovation of William Blake}

Before examining Vonnegut's approach to multimedia storytelling, it is worthwhile to consider the works of William Blake, which in many ways set the standard for the practice of interdisciplinary publication. Of course, a comprehensive dissection of Blake's graphic poetic output would require (and has required) volumes. For decades, scholars have theorized about the relationship between the illuminated manuscripts and Blake's personal and professional history — his career trajectory, religious philosophies, artistic influences, and political sympathies - to the point that critical analyses of Blake's illuminated works are as numerous and nuanced as the illuminations themselves. However, concerning its pertinence to a study of Kurt Vonnegut, two major factors of Blake's multimedia practice are worth establishing: their innovative redefinition of creative production, and their demonstration of word-image collaboration.

In many contexts of Blake criticism, scholars have identified a thread of revolution and invention, both literal and symbolic, in his multimedia creations. One ubiquitous trend across the catalogue of scholarship is that Blake's approach to, and execution of, the practice of manuscript publishing is historically unprecedented, and unmatched since his death. While the illuminated manuscripts can be considered revolutionary in the political sense of the word-for instance, in America: A Prophecy Blake engages in the literal discourse of political revolution — when approached as literary-art objects, the manuscripts also represent a prodigious achievement in both technical and philosophical imagination.

For the purposes of this discussion, the most important component of Blake's achievement lies in the physical act of publishing a work made solely by the artist's own hand. From a technical standpoint, this innovation revolves around the invention of a new 
printing method. Blake's lucrative experimentations with different kinds of metal plates, varnishes and acids resulted in his unprecedented ability to fuse text, illustration, color, and design into a single entity. His exact method of etching and printing was undocumented and therefore remains somewhat unclear and disputed among specialists—in fact, it remained a complete mystery until the 1940s when S. W. Hayter, Joan Miró, and Ruthven Todd experimented with recreating his methods. ${ }^{9}$ In any case, in inventing his own one-man printing operation, Blake found a way to etch image and text on the same plate, at the same time. ${ }^{10}$ Each manuscript page—and each complete manuscript itself—is therefore the holistic product of a single artist's mind and hand. Contrary to the disjointed assembly process of contemporary publishing, illustrating, and printing, and to hand-painted medieval illuminated manuscripts — the only near-precedent for Blake's illuminations—Blake appropriated the mechanics of industrialized printing to create a highly individualized, even anti-industrial, product.

What external or personal factors inspired Blake's technical originality remains a contested topic of discussion. According to the seminal lectures of Anthony Blunt, Blake's deviation from established engraving and printing methods implies more than scientific curiosity. ${ }^{11}$ In Blake's own words, his invention was instructed by a vision from Robert Blake, his beloved and recently deceased brother. ${ }^{12}$ This explanation is perhaps revealing of the emotional drive behind Blake's artwork, but offers little in terms of concrete explanation. Another suggested theory is that his technical originality arose out of necessity to serve his artistic individuality, which required that the entire process of conceptualizing, designing,

\footnotetext{
${ }^{9}$ Anthony Blunt, The Art of William Blake, (New York: Columbia University Press, 1959), 45.

${ }^{10}$ Martin Myrone, The Blake Book, (London: Tate Publishing), 2007), 65.

${ }^{11}$ Blunt, The Art of William Blake, 45.

12 Myrone, The Blake Book, 64.
} 
and crafting the manuscripts be executed by Blake himself. ${ }^{13}$ Besides the underlying spirit of revolution brewing in England at the time, the drive for artistic individuality arose from deficiencies, both economic and imaginative, in the eighteenth-century publishing market, which failed to suit Blake's artistic needs. His young interest in merging literary and visual craft required experimentation. As Morton Paley has suggested, the economic burden of routing poetic experiments through a professional letterpress made it more efficient to produce as much as possible in Blake's own workshop. ${ }^{14}$ Furthermore, the holistic nature of Blake's composite visual manuscripts was disrupted by the contemporary printing structure, which separated the tasks of writing, illustrating, and printing. Therefore, the solution to Blake's problematic aspirations of fusing text and design lay in the technical invention that could free him from third-party printers.

Whatever the reasons behind it, the implications of Blake's unique publishing method are inextricable from his sense of creative independence. Blake's artistic career began during a specific juncture of cultural and political change in Europe. The rapid growth of London's art scene in the 1760s encouraged experimentation in young artists, who for the first time could attempt to make a career out of personal expression rather than professionalized craftsmanship; ${ }^{15}$ meanwhile, the French and American revolutions inspired a spirit of upheaval and change in the European public sphere. Such cultural context has driven many scholars to argue that Blake's deviation from the standardized publishing process correlates with the spirit of revolution in his time. More pertinent to my examination, however, is the way in which Blake's illuminated manuscripts function as individualized artistic objects. His technical approach to book production exceeded the reach of London's established publishing

\footnotetext{
${ }^{13}$ Blunt, The Art of William Blake, 45.

${ }^{14}$ Morton Paley, William Blake (Oxford: Phaidon Press), 13.

${ }^{15}$ Myrone, The Blake Book, 53.
} 
industry, and defied the traditional categories of book or painting, residing somewhere in a new realm of interdisciplinary media. The resulting illuminated prints, as Martin Myrone notes, thus evade classification as either mass-produced or hand-made entities. ${ }^{16}$ As mechanically printed objects, the illuminated manuscripts are theoretically reproducible multiples of one another; yet, due to the variations in color and quality affected by Blake's hand-made approach, each distinct copy of a single manuscript exists as a unique art object. In his ability to blur the lines between illuminated books as many copies of an original and illuminated books as many unique originals, Blake distinguishes himself as a revolutionary artist and characterizes his unique position in the literary industry—one that is both cooperative with and in control of a literary market.

Blake's illuminated manuscripts also necessitate a reconsideration of the technical relationship between text and design when they are etched simultaneously. According to Joseph Viscomi, Blake's process of directly designing and producing illuminated pages as a cohesive body — as opposed to the standard practice of piecing together text and illustration before engraving a copying — allowed for an organic, rather than industrialized, creative product. ${ }^{17}$ In "composing" each illuminated page Blake demonstrated a holistic approach to design, etching and printing, which eschews the predetermined text-image relationships created by traditional printing. ${ }^{18}$ As such, we can neither assume that the images are meant to illustrate the poems nor that the poems are meant to describe the images. The resulting organic partnership between word and image on the page exemplifies the technical cohesion of Blake's practice and is central to the interpretive significance of multidisciplinary art.

\footnotetext{
${ }^{16}$ Myrone, The Blake Book, 65.

${ }^{17}$ Joseph Viscomi, Blake and the Idea of the Book (Princeton: Princeton University Press, 1993), 30.

18 Ibid., 31.
} 
Running parallel to his technical innovation, Blake's consolidation of the physical printing process also manifests a philosophical innovation in unifying separate artistic practices. In the larger context of word-image theory, Blake's manuscripts are one of the earliest of examples of what scholars consider to be "composite" productions. W. J. T. Mitchell cites the medieval illuminated manuscript as the only possible historical precedent for Blake's manuscripts, but even in the Middle Ages the tasks of writing, copying, and illustrating were kept separate. ${ }^{19}$ Blake's uniqueness is due to his unprecedented total control over the creation process, both in terms of content and physical product. This sense of control over artistic practice situates Blake both within and beyond his contemporaries. While the eighteenth century was obsessed with theories of unity and the spiritual whole, Blake expounded on the ideas of his time to craft an artistic philosophy in which the media of painting and poetry must be synthesized so as to elevate one another and produce a truer representation of the artist's vision. ${ }^{20}$ Mitchell creatively describes the effect as "multiplying [painting and poetry] by one another"- the images are not additions to the poems, nor are the poems additions to the images; rather the two art forms transcend their duality to create a unified product that is greater than either of its parts. ${ }^{21}$

Such a bold redefinition of the publishing process is even more radical when considering the larger Romantic skepticism about the printed word. Besides Blake's creative achievements, Mitchell notes a distinct separation from the philosophies of his contemporaries, such as Wordsworth and Coleridge, who relentlessly decried the printed

\footnotetext{
${ }^{19}$ W. J. T. Mitchell, Blake's Composite Art: A Study of the Illuminated Poetry (Princeton: Princeton University Press, 1978), 15.

${ }^{20}$ Ibid., 17.

${ }^{21}$ Ibid., 31.
} 
word as a poor substitute to oral tradition. ${ }^{22}$ Blake certainly acknowledges this hesitation in his poetry with themes of inspiration and its corruption-recall one well-known interpretation of his "Piping Down the Valleys Wild," in which the plucking of a reed and staining of the water signals the loss of creative purity in the printing and marketing of poetry. Nevertheless, Blake certainly did stain the waters and, rather than flounder in anxiety over the printed word, he embraced the full potential of "visible language" in his unlicensed printing to subvert the artistic corruptions of the publishing industry. ${ }^{23}$ Moreover, the trend of united abstract and concrete representation (the verbal and the visual) throughout Blake's publications suggests an ideology of harmony, rather than corruption, in the art of book publishing - for example, in Jerusalem God's speech to Moses results in the gift of writing; meanwhile, the Piper rejoices that through writing his songs will continue to be heard. ${ }^{24}$ To the extent that graphic arts and written word represent the same abstract-concrete duality of human perception, the multimedia works of William Blake make a similar attempt at artistic wholeness.

The culminating effect of Blake's hand-made publications is one that reinforces the supremacy of the artist and expression of the artist's unique identity. In keeping with Romantic philosophy, Blake's art strives to illuminate the individual, to move inward towards expressions of the mind, and to promote a unique creative identity through works of art.

According to Morris Eaves, one significant factor in the transition from the Enlightenment to Romanticism is the growing importance of the artist in judging the value of a work, "emphasiz[ing] the connection between the expressive powers of the artist and the expressive

\footnotetext{
${ }^{22}$ W. J. T. Mitchell, Picture Theory (Chicago: University of Chicago Press, 1994), 119.

${ }^{23} \mathrm{lbid} ., 121$.

24 Ibid., 129.
} 
qualities in the work." ${ }^{25}$ In other words, artistic identity becomes a central element in artistic production, inseparable from the work itself. Blake's philosophy of artistic unity depends on the supreme expression of his individual self, and therefore demands that his work be untainted by the marks of other artists. ${ }^{26}$ Therefore, it is only by taking total control of artistic production - from the imagination to the printed book - that an untainted, unique self could be expressed.

These critical trends reaffirm Blake's alignment with the movements of his time, but suggest that in many ways he surpassed the efforts of his contemporaries. Besides reimagining the physical process of book-making, Blake lauded the printed publication as a vehicle for, rather than a hindrance to, the expression of completely individualized artistic identity. Moreover, his revolutionary genius lies in the commitment to the mental and physical consolidation of two traditionally distinct media: text and image. More than a hundred and fifty years after Blake's groundbreaking career, the interplay of text and image continues to transcend the boundaries set by "traditional" publishing in the work of Kurt Vonnegut. Though Blake cannot be viewed as a model for the artistic goals of anyone other than himself, his life work nevertheless provides a necessary point of comparison for a more current multimedia publication.

\footnotetext{
${ }^{25}$ Morris Eaves, William Blake's Theory of Art (Princeton: Princeton University Press, 1982), 51.

${ }^{26}$ Ibid., 175.
} 


\section{Part Two: Reconsidering Breakfast of Champions}

To insinuate a connection between the work of Kurt Vonnegut and that of William Blake may seem absurd at first. By many standards, their artistic identities are nearly opposite. As a philosopher, Blake moved deeply within Romanticism, formulating ideas of spiritual and physical unity, individualism, and personal realization; meanwhile, Vonnegut's literature is filled with messages of disunity, nihilism, and personal insignificance. Blake exceeded the limitations of his century's established publishing industry to create unprecedented literary products, while Vonnegut, even with his cynical voice, came to success well within the American literary market. As a visual artist, Blake drew from classical precedents and filled his illuminated pages with baroque, encompassing designs; Vonnegut, in his personal drawings and in the illustrations to Breakfast of Champions, tended toward single-line doodles, often bare and abstracted.

So it is true that any direct comparison between William Blake and Kurt Vonnegut would be a useless endeavor. However, certain aspects of the word-image dynamic exemplified by the composite works of Blake extend beyond a Romantic context and are certainly at play in a work like Breakfast of Champions. Like Blake's illuminated manuscripts, which made a bold proposition against the Romantic skepticism toward images and idolism, ${ }^{27}$ Breakfast of Champions emphasizes through demonstration the importance of visualization both in contemporary American culture and in postmodern ideology. Where Blake inserted himself into the debate between the primacy of oral tradition and the functionality of the printed word, Vonnegut boldly explores the tension between power and ineffectuality through word and image. And ultimately, like Blake, Vonnegut makes an overt

\footnotetext{
27 Mitchell, Picture Theory, 119.
} 
(if more pessimistic) attempt at creative expression of the self by assuming complete creative control over his novel.

At the heart of Breakfast of Champions is a seemingly manic, though actually highly calculated, gesture toward self-expression and self-definition. Interwoven with themes of visual culture and misdirection, these dynamics are essential to an appreciation of Vonnegut's underestimated novel, and all of them revolve around the deliberate use of illustration in creating a composite work.

\section{$\underline{\text { The Illustrations in Context }}$}

Outside of his literary career, Vonnegut dabbled in the visual arts with a unique and sophisticated style to match his off-beat prose. The entire cache of his surviving drawings has been published with accompanying remarks by Nanette Vonnegut, an artist and daughter of the author. Among the memories she shares of her father's artworks, Nanette describes the importance of "doodling" to Vonnegut family history. Along with his sister and father, Kurt adopted the title of "Grand Master Doodler," internalizing what Nanette calls "the secret joy of doodling in a dreadfully serious world." ${ }^{28}$ She recalls other details about the ubiquity of art in her own childhood, from the slogans her father painted on the walls of their home, to the murals she and her siblings attempted in following suit, to the collection of books on artists that she calls her father's "angels"—Al Hirschfield, Stan Laurel, Paul Klee, and, yes, William Blake. ${ }^{29}$ In Vonnegut's own words, "The making of pictures is to writing what laughing gas is to the Asian influenza." ${ }^{30}$ To the minimal extent that Vonnegut's murky biography can bear

\footnotetext{
${ }^{28}$ Kurt Vonnegut, Nanette Vonnegut, and Peter J. Reed, Kurt Vonnegut Drawings (New York: Monacelli Press, 2014), 9.

${ }^{29}$ lbid., 10.

${ }^{30} \mathrm{Ibid}$.
} 
inference on his literature, there seems at least to be a great respect on Vonnegut's part for the power of the visual arts. Vonnegut's independent drawings deserve substantial consideration on their own, but even the irreverent doodles in Breakfast of Champions are born from the mind of a thoughtful artist.

In approaching Breakfast of Champions, the placement and function of drawings within the text must be preliminary considerations. The obvious assumption is that they serve in an explanatory capacity as direct, though crude, illustrations of the narrator's words. Breakfast's narrative voice is both naive and clinical in its descriptions of life on Earth-like an ethnographer from another galaxy describing the culture of an extinct planet - and the simple drawings are overtly situated to demonstrate the narrator's observations. As William R. Allen puts it, Vonnegut adopts "the perspective of someone who must explain everything, ... draw [ing] pictures for his readers - of a chicken, a cow, a hamburger, a Holiday Inn, and, most infamously, of his rectum." ${ }^{31}$ As another critic, Charles Berryman, describes, Vonnegut's "tone is deliberately simpleminded," and, paired with superfluous doodles of everyday objects, offensive to many readers for sounding too much like a condescending user's manual to a pessimistic life on Earth. ${ }^{32}$

However, it should be noted that Breakfast is perhaps too conspicuous in its manual style to be taken at face value, and that Vonnegut's inclusion of personalized illustrations fulfills a subtextual function. In light of Vonnegut's tendency toward satire and parody—not to mention painstaking self-awareness - his childish drawings call attention to more than just the objects they depict. Previous critics have suggested that in reducing the often overlooked elements of daily life to their most basic visual forms, the drawings accomplish a goal that is

\footnotetext{
${ }^{31}$ Allen, Understanding Kurt Vonnegut, 107.

32 Berryman, "Comic Persona," 165.
} 
common to much of Vonnegut's fiction: "not to titillate but to allow the reader to see through convention." 33 They illuminate what Jerome Klinkowitz calls "the simple essence of a thing, and ... its inexorability ... in a manner so plain that we are forced to see what rhetoric and myth obscures." ${ }^{34}$ Breakfast of Champions as a whole works towards a similar goal of exposing the absurdity beneath the conventions we take for granted, and Vonnegut's crude use of redundant imagery helps to underscore this purpose.

The underlying implication here, which follows the thread found in the history of composite publications, is that images convey a kind of meaning that text alone cannot. In the novel's preface, the narrator explains his reason for illustrating this particular story:

I am programmed at fifty to perform childishly - to insult "The Star-Spangled Banner," to scrawl pictures of a Nazi flag and an asshole and a lot of other things with a felt-tipped pen ... I think I am trying to clear my head of all the junk in there- the assholes, the flags, the underpants. Yes - there is a picture in this book of underpants ... I think I am trying to make my head as empty as it was when I was born onto this damaged planet fifty years ago. ${ }^{35}$

In this instance, drawing facilitates a kind of psychological purge. Speaking of his relationship with the author and his artworks, Peter Reed suggests that whatever constraints plagued Vonnegut as a writer he was able to circumvent with doodles, allowing his creative genius to surge forth uninhibited. ${ }^{36}$ Elsewhere, Kurt's daughter Nanette has postulated, "I believe my father forgot about the War when he doodled." ${ }^{17}$ These explanations, though dismissive of a more sophisticated narrative function, are nevertheless revealing of the importance that image have in the human mind. In any case, it is clear that the illustrations in

\footnotetext{
${ }^{33}$ Allen, Understanding Kurt Vonnegut, 107.

34 Jerome Klinkowitz, Kurt Vonnegut (New York: Methuen, 1982), 71.

${ }^{35}$ Vonnegut, Breakfast, 5.

${ }^{36}$ Vonnegut, Drawings, 19.

37 Ibid., 10.
} 
Breakfast are intended to add a dimension of the author's psychology to his prose that cannot be delivered in a traditional text.

The illustrations are born of Vonnegut's own imagination and hand, and not a third party illustrator's. In addition to conveying a dimension of thought that text cannot, these drawings convey a dimension of personality that is uniquely Vonnegut's and therefore could not possibly be replicated by another author. This element of individuality is compounded by the narrative content of the novel, in which many critics have noticed an overflow of autobiographical impulse. According to Charles Berryman, Vonnegut's early-career divorce from drama and television was caused by his dissatisfaction with film's tendency to erase the author, a problem which he remedied in his fiction with a ubiquitous, self-referential narrative voice. ${ }^{38}$ Evolving from the autobiographical prefaces in many of his earlier works, in Breakfast of Champions Vonnegut goes so far as to converse with himself (" "This is a very bad book you're writing,' I said to myself . . . 'I know,' I said."), ${ }^{39}$ and ultimately to include himself as a participatory character in the novel's climactic actions. In a novel that revolves around a parody of Vonnegut's autobiography (the life of a nihilistic science fiction writer), the ubiquitous hand-drawn illustrations provide yet another layer of the author's creative thumb print. As I will discuss further on, a similar individualistic personality appears in the composite works of William Blake and goes hand in hand with the decision to self-illustrate.

More so than Vonnegut's earlier novels, Breakfast of Champions is conspicuously marked by the author's identity. It is saturated with imagery whose untrained style and squiggly imperfections bear witness to authenticity. Moreover, the novel's preface assures that the subject matter for the novel's visual content is dredged directly from the author's own

${ }^{38}$ Berryman, “Comic Persona," 162.

${ }^{39}$ Vonnegut, Breakfast, 193. 
mind, like "a sidewalk strewn with junk, trash which I throw over my shoulders as I travel in time back to November eleventh, nineteen hundred and twenty-two," (the day of Vonnegut's birth) ${ }^{40}$ Whether a sincere attempt at autobiography (albeit buried beneath several layers of sarcasm), or a mocking jab at all the critics and readers who treated its parodied philosophy with serious consideration, Breakfast of Champions embarks on an unconventional narrative mission of self-expression—one that is dependent on the text's fusion with images.

\section{The Symbolic Function of Images}

The notion of enhancing text with illustration is in no way a new idea, but the manner in which illustrations are executed can greatly change the way they function in relation to the text. This variability has been often noted in the works of William Blake, and is essential to the notion of word-image collaboration. In defining the nature of a truly composite work, one of the central distinctions that W. J. T. Mitchell makes is between "representational" and "symbolic" illustrations. Referencing Blake's contemporaries and predecessors, he notes that "the belief in the translatability of literature into painting is everywhere evident in the eighteenth century's liking not only for individual designs illustrating literary texts but for entire galleries devoted to the pictorial translation of poets," suggesting that the conversion from word to image and vice versa "was possible and even inevitable." ${ }^{41}$ Whereas the tradition of illustration was to depict representationally the events of a written narrative, Blake instead illustrated "symbolic recreation[s] of the ideas embodied in [a] scene ... actually contribut[ing] to the symbolic content of the poem through his own personal interpretation." ${ }^{" 42}$ In this sense, Blake's illustrations produce their own body of interpretive

\footnotetext{
${ }^{40}$ Ibid., 6

${ }^{41}$ Mitchell, Blake's Composite Art, 18.

42 Ibid., 18.
} 
content in relation to its text, rather than simply restating visually what has been said verbally.

This distinction between representative and interpretive symbolism is crucial to a reading of Breakfast of Champions, which actively demonstrates (rather than restates) the importance of visualization and its central role in human life. This interpretation is so elementary — pictures serving to highlight the role of imagery — that its importance to the novel as a whole may be easily overlooked, partly because the illustrations pretend to be simpler than they really are. On the surface it would seem that Vonnegut's rudimentary doodles are indisputably representational. They are neither complex nor subtle, and each one appears uniformly after some variant of the phrase, "It looked like this." Ostensibly, the doodles exist solely for the purpose of direct visual translation, leaving some previous scholars to claim that their larger function is merely to underscore the critical, didactic tone of the text. While they certainly do reinforce the narrator's clinical descriptive tone, the illustrations also subversively achieve symbolic engagement with the text, much like the kind that Mitchell ascribes to Blake. To see this symbolic function clearly, one must look more closely at the novel's narrative approach, and where and why Vonnegut peppers it with imagery.

The novel's first chapter provides an excellent example of Breakfast's narrative goal. It is essentially a history of the United States, stripped down to its most basic elements and narrated to an audience in the distant future with none of the knowledge, associations, or assumptions held by contemporary Americans. While the short history seems innocent and objective in its deadpan delivery, Vonnegut's underlying cynicism and critique are easily detectable. Among the elements of American history that the narrator chooses to recount are: 
the lyrics to the national anthem, which he describes as "pure balderdash," and "gibberish sprinkled with question marks;" ${ }^{43}$ the national motto, E pluribus unum, which he critiques for having nothing to do with actual American life ${ }^{44}$ the narrative of exploration and colonization, which he refers to as a conquest of "sea pirates;" 45 and the various weaponry of the sea pirates, including gunpowder, boats, and — the most dangerous—-"their capacity to astonish." 46

The overarching narrative technique established in the first chapter and carried out throughout the novel is to describe familiar elements of contemporary life in a seemingly objective manner in order to reveal the underlying absurdity in it all—for modern audiences, a kind of truth-telling revision of everything we thought we knew. Of course, Vonnegut's version of American history is driven by his various ideologies, not to mention a literary agenda, and is hardly more trustworthy than the version he critiques. This essential hypocrisy in Vonnegut's approach — and what's more, hypocrisy delivered in a condescending toneelicited many of the scathing reviews that the novel received. Still, as an unconventional literary technique, Vonnegut's faux user's guide to life on Earth makes for a provocative attempt at self-awareness and social critique. While this brand of nihilistic critique and cynicism are central to most Vonnegut novels, the conspicuous addition of illustrations makes Breakfast of Champions unique.

Spattered throughout the first (and every subsequent) chapter are the author's doodled illustrations of the everyday objects and concepts that the narrator explains to his imaginary audience. Given their extreme simplicity—and, to a contemporary audience already

\footnotetext{
${ }^{43}$ Vonnegut, Breakfast, 8.

${ }^{44}$ Ibid., 9.

${ }^{45}$ Ibid., 10.

${ }^{46}$ Ibid., 12.
} 
experiencing day-to-day life on Earth, their redundancy - the illustrations appear to require little consideration beyond their representational function. Alongside the written narrative's barely concealed scorn for modern life, Vonnegut's drawings might simply be condescending doodles to match a condescending narrative voice. However, this common interpretation stops too short of the images' underlying function, and places far too much faith in Vonnegut as a face-value author.

At face value, Vonnegut's illustrations pretend to play a functional, empirical, and essential role in the narrator's process, but in fact the visual demonstrations that accompany the text are often unnecessary. A large, rectangular restaurant sign displaying the word "EAT" could be thoroughly described in words, as I just did. Instead, Vonnegut draws the sign to replicate its effect on the characters who see it and their subsequent response to the visual prompt: "So they ate." ${ }^{47}$ In fact, many of the drawings in Breakfast of Champions could be just as easily described in words. Vonnegut draws a handful of other signs, only barely distinguishable from one another except for their changing messages: "Bluebird Farm,"48 "Visit Sacred Miracle Cave, 52 mi.,"49 "You are now entering the City of Brotherly Love," ${ }^{50}$ etc. He repeatedly draws semi-trucks, similar except for their company labels: "Ajax,"51 "Pyramid,"52 "Hertz,"53 and "Peerless, Peerless." ${ }^{54}$ Most unnecessary, he includes several "drawings" that are simply phrases handwritten on the page--"You ought to be president of the United States," 55 or "What is the purpose of life?"56 or "E = MC ${ }^{2157}$

\footnotetext{
47 Ibid., 89.

${ }^{48} \mathrm{Ibid} ., 118$.

49 Ibid., 114.

${ }^{50} \mathrm{Ibid} ., 102$.

51 lbid., 91.

52 Ibid., 90.

${ }^{53} \mathrm{lbid} ., 205$.

${ }^{54}$ Ibid., 197.

55 Ibid., 36.
} 
As representational images, then, the illustrations in Breakfast are totally useless. To a contemporary reader they restate the obvious - we don't need pictures to know what the narrator means by "flamingo," or "pea," or "electric chair," - and even in the context of the imaginary audience, supposedly unfamiliar with these basic concepts, everything that Vonnegut draws could be just as easily described in a sentence. The logical result, then, is that the true function of the drawings is not to convey literal representation, but to symbolically enhance the themes of the text.

One such symbolic function is to demonstrate the nearly subconscious role of nonverbal symbols in constructing our experience of life. Consider, for instance, the illustrations in the first chapter alongside the narrator's revised history of the United States. The first illustration is of an American flag, preceding a sarcastic explanation of the taboo of lowering the flag, or "flag-dipping." ${ }^{58}$ (This serves as a provocative contrast to a later drawing of Nazi flag__"When the Germans were full of bad chemicals, their flag looked like this"). ${ }^{59}$ Another is a picture of a torch, or "an ice-cream cone on fire," which the narrator equates with the "piece of evil nonsense" known as the American beacon of freedom. ${ }^{60}$ More absurd, since it could have just as easily been typed, is a large hand-written "1492," which the narrator explains was written on blackboards to be memorized by children who were given a false version of colonial history. ${ }^{61}$ Besides simulating the didactic tone on which the novel hinges, these drawings reveal the centrality of images to the way humans learn, as well as the abstract concepts that the images arbitrarily convey. The entire humor of this opening chapter

\footnotetext{
56 Ibid., 67.

57 Ibid., 241.

58 lbid., 9.

59 Ibid., 133.

60 Ibid., 10-11.

61 Ibid., 10.
} 
revolves around the differences between what most readers will associate with a given image (e.g., a torch) and the written descriptions that Vonnegut provides (e.g., an ice-cream cone on fire). Vonnegut thereby constructs a word-image relationship in which both entities, independently charged with assumed meanings, are comically at odds with one another.

In this way, the images prove to be the opposite of representational, because they are highly misleading. Their place in the text must then assume a symbolic role in forwarding Vonnegut's larger philosophy on visual culture - the images themselves are arbitrary but their existence within the text calls attention to the prevalence of images in our lived experience. In other words, while the written content of the first chapter exposes some of the irony and absurdity in what contemporary Americans take for granted about their arguably false history, the presence of images highlights the ubiquity of visual culture in propagating that false history. This equally weighted interplay between text and imagery established in the first chapter continues throughout the novel and should inform the rest of its interpretation.

The symbolic importance of visualization may also be seen in the textual narrative itself, where Vonnegut's distaste for iconic recognition sometimes takes a metaphorical stance. For example, in another critique of the "sea pirates," he goes on to suggest the disturbing role of visualization in creating and implementing racial politics. After debunking the myth of American freedom, the narrator says,

The sea pirates were white. The people who were already on the continent when the pirates arrived were copper-colored. When slavery was introduced onto the continent, slaves were black.

Color was everything. ${ }^{62}$

62 Ibid., 11. 
The simple recognition that "color was everything" emphasizes yet another dimension of visual power in manipulating the human experience. Regardless of written history or explanation, the most persistent perpetuator of racial distinction (and its deplorable sideeffects) is visible color. Once again, Vonnegut forefronts his narrative with conspicuous critique of what we see versus what we read or what we know.

A heavy-handed critique of visualization — or visual propaganda, as it could just as easily be called—was undoubtedly at play in William Blake's conception of composite works as well. Reacting to critiques of the French Revolution, many of Blake's contemporaries distanced themselves from the runaway fervor created by image-based philosophies (which by their definition included the printed word). ${ }^{63}$ Mitchell describes the English leaning toward iconoclasm as a reactionary policy against "idolism, the tendency to worship our own created images." ${ }^{64}$ Rather than run from the controversy, Blake appears to have embraced the tension between iconoclasm and idolism by appropriating images and words alike in his mission for artistic expression. In a most obvious example, Blake's introduction to Songs of Innocence implies some of the fears expressed by Romantic artists: that the purity of heavensent inspiration might be corrupted by mass production, or that oral poetry and natural beauty must be tainted as the price for sharing them. But in light of these anxieties, Blake chose to explore the tensions between oral tradition and print publishing through the medium of illuminated manuscript, which may be taken as a sign of optimism. ${ }^{65}$ Vonnegut seems to be invoking a related fear, whereby the perpetuation of injustice and misinformation is as simple as a visual icon (a torch of freedom, an American flag, or a large-print "1492"), and in expressing this fear he too resorts to the very tools he critiques: word and image.

\footnotetext{
${ }^{63}$ Mitchell, Picture Theory, 118.

${ }^{64}$ Ibid., 119.

65 Ibid., 122.
} 
In this instance, the impetus behind the composite works of both Blake and Vonnegut seems to be a gesture toward self-reflexivity. As participants in the visual and literary arts, who better to ruminate on the relationship between word and images? And in critiquing the nature of words and images, what better way than to demonstrate their relationship firsthand? Though we can only speculate as to the inspiration or reasoning behind Blake's or Vonnegut's composite practices—not to mention the dubious similarity between the twothere is undoubtedly a deeper symbolic and critical motion behind Vonnegut's choice to illustrate his text.

A critique of images in Vonnegut's hands, then, may be more of a cynical observation than a hard line in the sand. The choice to illustrate Breakfast of Champions demonstrates the more neutral truth about human experience and storytelling, which is on the one hand abstract and verbal and on the other hand image-based. In some instances, Vonnegut presents this duality as humorous. For example, he explains the possible confusion surrounding the word "beaver" by first doodling a large rodent ("It loved water, so it built dams.") followed by a crude rendering of a vagina ("This is where babies come from."). ${ }^{66}$ Later he depicts the various forms denoted by the word "chicken," one being a living, flightless bird, the other being a bucket of deep fried meat. ${ }^{67}$ In other instances, such as the opening chapter's U.S. history lesson, the duality becomes sinister-images as harmless as "an ice cream cone on fire" and as absurd as a pyramid with an eye on top serve to conceal a violent and misrepresented history. In either case, Vonnegut establishes from the novel's outset words, images, and their mutual associations are subject to skepticism and confusion. Nevertheless,

\footnotetext{
${ }^{66}$ Vonnegut, Breakfast, 23.

${ }^{67}$ Ibid., 157-158.
} 
both are a vital part of shaping artistic communication, and are therefore equally important in the conveyance of a multimedia novel like Breakfast of Champions.

According to Vonnegut's preface, the act of doodling throughout his book is merely a purge of the subconscious, "to make my head as empty as it was when I was born onto this damaged planet fifty years ago." ${ }^{68}$ While oversimplifying the scope of imagery in personal and public life, this statement does reinforce the notion that images lie just as heavily on the mind as the words, ideas, and abstract concepts that make up a traditional piece of writing. Breakfast of Champions serves as a receptacle and vehicle for both sides of this duality. Therefore, in the effort to do no more than "write about life" and "bring chaos to order," it would seem that Vonnegut's novel, just like the human histories and minds it critiques, would be incomplete without its visual component.

\section{Word and Image at Odds}

The illustrative component of Breakfast of Champions signals a conscious engagement with the nuances of storytelling and communication, acknowledging that the tradition of the written word alone is in a sense incomplete without its relation to visualization. Breakfast of Champions, while hiding behind a veil of irony and sarcasm, therefore makes a bold attempt at reconciling visual and written understanding in a postmodern context. However, this reconciliation depends as much on the symbiotic relationship between images and words as it does on their shortcomings as a not-so-unified whole. Throughout the novel, the relationship between word and image receives a double, and somewhat self-contradicting, treatment, represented on the one hand as beneficial and necessary to a description of human life, and on the other hand as absurd and irrelevant. In

${ }^{68}$ Ibid., 5. 
many cases, the images themselves conceal an underlying sense of misrepresentation or confusion, complicating the reliability — and therefore functionality—of an illustrated text. Ultimately, Vonnegut balances his image-positive project with a healthy dose of criticism and pointlessness.

The first clue to this self-contradictory philosophy appears as a major recurring detail in the life and work of Kilgore Trout, the novel's protagonist. An absurdist science-fiction novelist, Trout is a half-satirical, half-autobiographical reference to Vonnegut himself. Trout's professional process as a writer is as nihilistic as the stories he writes. At the outset of Breakfast, Trout has written one-hundred and seventeen novels and over two thousand short stories, none of which he makes extra copies of, all of which he mails out to random magazines throughout the country with no hope of return. Ultimately, the majority of Trout's novels are published inside pornography magazines, their titles altered and their publication details not shared with the author.

Tellingly, only one aspect of this ridiculous career approach offends the fictional author: "Most distracting to Trout, however, were the illustrations his publishers selected, which had nothing to do with his tales." ${ }^{69}$ The narrator relays one of Trout's stories about a scientist who learns to replicate his cells in chicken soup, resulting in a nationwide ban on the owning of chicken soup by unmarried persons. Meanwhile, "The illustrations for this book were murky photographs of several white women giving blow jobs to the same black man, who, for some reason, wore a Mexican sombrero." ${ }^{70}$ Another of Trout's books entitled Plague on Wheels, his most popular publication, is published in a magazine entitled "Wide

\footnotetext{
69 Ibid., 21.

70 lbid., 22.
} 
Open Beavers," whose illustrations may be easily inferred. Throughout the novel, we learn of countless other Kilgore Trout stories and their irrelevant pornographic illustrations.

The cynicism in this aspect of the story is easy to spot. Despite his prolific output of ideas, and despite the dramatic effects of those ideas on the other characters in the novel, Kilgore Trout is powerless as an author to control the reception of his work, to the point that it is only consumed by accidental audiences in search of pornography. The absurdity of Trout's situation is compounded by a larger skepticism surrounding words and images, and their relation to one another. In Trout's situation, the correlation between his stories and their visual companions is not only random, it is totally ineffectual and hindering to both media. On the one hand, those audiences seeking pornographic images must be confused by the addition of bizarre science fiction allegories in between the pictures. On the other hand, those few but devout fans of Trout's fiction must wade through pornographic content in order to consume his work. Thus, the pseudo-doppelgänger that Vonnegut constructs for himself in the figure of Kilgore Trout is made all the more absurd at the mercy of word-image pairings.

In another brief episode of Trout's life, inside a restroom at a pornographic movie theater, Vonnegut places more evidence of the impotence of imagery. On the wall of the restroom, Trout sees scrawled in pencil, "What is the purpose of life?"71 Rather than quoting this message in type, Vonnegut chooses to hand-write it largely on one of the novel's pages. As discussed above, the impulse to "illustrate" rather than describe this message suggests the importance of its visibility to Trout. The message was not asked in person to Trout, nor was it printed in a book, it was scrawled by a human hand in an unlikely place. Similarly, Vonnegut scrawls the message in his own hand in an unlikely place, emphasizing not only the message's philosophic question but also its visual mark on the world. However, the

${ }^{71}$ Ibid., 67. 
importance of visual marking as a form of communication is undercut by the response that follows: "Trout plundered his pockets for a pen or pencil. He had an answer to the question. But he had nothing to write with, not even a burnt match. So he left the question unanswered."72

As I will discuss later, the answer Trout would have written had he found the proper utensil is revealing in its own right of some of the creative philosophies behind Breakfast of Champions, but for now it is important to note another kind of ineffectuality in visual communication. Mocking though he may be (how ridiculous that the purpose of life be knowable at all, let alone answered via restroom graffiti), Vonnegut relates in this passage an underlying pessimism in the same visual communication he emphasizes. Despite the crucial role that visual communication plays in transmitting ideas across time and space, it is ultimately only as powerful as one's ability--or willingness--to produce it. In the exaggerated irony of this situation, something as valuable as the answer to the purpose of life is left unsaid simply for lack of a writing utensil. Or furthermore, its effectuality might be thwarted by the randomness of its future audiences - the clientele of an adult movie theater-just as are the rest of Trout's insightful novels. In this scenario, all the potential powers of marking and visualization are proved fallible and useless.

The philosophies of Kilgore Trout and their inability to reach an appreciative audience are irreversibly tangled in Vonnegut's own tongue-in-cheek criticism of his literary career. Elsewhere in the novel, though, are more general examples of the kind of confusion that plagues word-image relations. As mentioned above, Vonnegut often plays with the differences between a single word and its many visual associations. For instance, he explains the multiple meanings of the words "beaver," one a kind of animal and one an anatomical

72 Ibid., 67. 
euphemism; ${ }^{73}$ "beetle," both an insect and a popular car $;{ }^{74}$ and "chicken," in one state a bird, in another a bucket of fried meat. ${ }^{75}$ In other instances, he illustrates the visual inconsistencies between two supposedly like things - for instance, the visual incongruity between a cow and a hamburger ${ }^{76}$ or between architectural pyramids and a trucking company arbitrarily named "Pyramid." ${ }^{17}$ Or in other instances, his drawings are simply incorrect. Above a crudely sketched ruler-inch — meaning two vertical lines separated by a series of smaller, evenlyspaced vertical lines- the narrator explains, "This is an inch." ${ }^{78}$ In fact, the sketch is much longer than an actual inch, illustrating that the symbolic visual cue for an "inch" and a literal inch-length are not necessarily conjoined.

Similar to the mention of race as an arbitrary, but persistent, visual factor in human behavior, Vonnegut includes another example in which visual signs are misconstrued to woeful effects. The novel's second protagonist, Dwayne Hoover, owns a dog named Sparky who, because of an automobile accident, is unable to wag his tail. As the narrator sadly explains, ". . . he had no way telling other dogs how friendly he was. He had to fight all the time. His ears were in tatters. He was lumpy with scars. ${ }^{79}$ Here, as with the earlier acknowledgement that "color was everything," the complexities of an individual's personality and behavior are boiled down to a single visual symbol whose inadequacy comes with grave consequences.

A culminating example of conflicted natures of imagery can be seen in the novel's two-part title, "Breakfast of Champions, or Goodbye Blue Monday." On the first of three title

\footnotetext{
73 lbid., 23.

${ }^{74}$ Ibid., 134-135.

75 Ibid., 157-158.

76 Ibid., 124.

77 Ibid., 109.

${ }^{78} \mathrm{Ibid} ., 144$.

79 Ibid., 17.
} 
pages is a drawing of a t-shirt with the phrase "Breakfast of Champions" on its front, which as the first paragraph of the preface explains,

. . . is a registered trademark of General Mills, Inc., for use on a breakfast cereal product. The use of the identical expression as the title for this book is not intended to indicate any association with or sponsorship by General Mills, nor is it intended to disparage their fine products. ${ }^{80}$

Besides demonstrating again how easily a verbal or visual symbol can be divorced from its original purpose, the title page immediately calls to mind the ubiquitous position of visual messages - for example, a slogan on a t-shirt—in American consumer culture. The second title page features only a giant hand-written "Or," surrounded by many star-like shapes which are later explained to be Vonnegut's artistic interpretation of an anus. The third title page features of drawing of cow below a large speech bubble which reads, "Goodbye Blue Monday." At first an inexplicable addition to the novel's title, the significance of this phrase is revealed a few chapters in. The narrator relates that Dwayne Hoover, the novel's secondary and mentally unstable protagonist, once painted the phrase on the side of bomb that was to be dropped on Hamburg, Germany in World War II. This experience was the extent of Hoover's military involvement.

In the combined title, Vonnegut thus presents two examples of power through marking: one is a harmless phrase on a t-shirt or cereal box that has nevertheless infiltrated the entirety of American popular culture; the other is a harmless phrase written by a stranger on the side of a bomb which would nevertheless destroy countless lives and properties in a distant country. The destinations of these markings — that is, a visually transmittable

${ }^{80}$ Ibid., 1. 
messages created by a human hand - are thus pitifully easy to enact and yet unfathomable far-reaching, for good or for evil.

In light of these dualities surrounding visual communication and its effectiveness, the inclusion of illustrations in Vonnegut's text carries a tangled web of significance. On the one hand, Breakfast of Champions seems to exalt the position of images as powerful (or harmless) vehicles of ideology and education, as outlets for the human mind's accumulated baggage, and as safeguards against the frequent confusions brought on by written language. At the same time, Breakfast of Champions repeatedly demonstrates the major confusions that occur when assuming meaning from images alone, as well as the destructive power in visual marking. Despite its potential as language's co-dependent, visual communication proves in many cases to be sinister in its susceptibility to manipulation. This duality must necessarily complicate any critical approach to Breakfast of Champions as a conspicuously illustrated text. Given these conflicting - even paradoxical — portrayals of the relationship between word and image, what then do we make of Vonnegut's decision to bring them together?

\section{Composite Self-Expression}

Despite the sense of pessimism and contradiction that floods Breakfast of Champions, it is most important to remember that we are hearing the words of a fictitious narrator, not Vonnegut himself, and therefore Vonnegut must be considered on his own terms. The narrator bemoans the poor state of modern art and publishing, thanks to which the novels of our protagonist are lost between the pages of pornographic magazines. Vonnegut, however, is no Kilgore Trout. Before Breakfast of Champions his books had sold incredibly well, and without the help of pornography. As much as the narrator likes to highlight the fallibility of images, Vonnegut himself (unlike Trout) was not subject to their misuse, for in Breakfast of 
Champions he actively chooses to create and place the images himself. Despite the heavy critique dealt to images in this novel, it was Vonnegut who chose to give them ubiquitous presence throughout. The decision to illustrate is not a common practice to which Vonnegut grudgingly bends - it is highly uncommon and therefore deliberate. Moreover, while the narrative of Breakfast of Champions is dominated by chance, absurdity, and miscommunication, Vonnegut's illustrative choices signal a complete creative control over the finished product. The ultimate effect of this finished product is an act of self-expression.

Without its illustrations, Breakfast of Champions would still mark an unprecedented move toward self-conscious expression. Early on, the narrative voice begins a twisted game of self-awareness when, disrupting his own lecture about body bags ("A new invention"), the narrator reveals:

I do not know who invented the body bag. I do know who invented Kilgore Trout. I did.

I made him snaggle-toothed. I gave him hair, but I turned it white. I wouldn't let him comb it or go to a barber. I made him grow it long and tangled.

I gave him the same legs the Creator of the Universe gave to my father when my father was a pitiful old man. They were pale white broomsticks. They were hairless. They were embossed fantastically with varicose veins. ${ }^{81}$

The narrator's admission of his own presence continues to grow throughout the novel, as he confesses about Trout, "I had given him a life not worth living, but I had also given him an iron will to live." 82 The awareness spreads to the artificiality of the novel, and the narrator's conscious doubts: " 'This is a very bad book you're writing,' I said to myself . . . 'I know,' I said." 83 This progression culminates in the narrator's statement of purpose- "I would bring

\footnotetext{
${ }^{81}$ Ibid., 32.

82 Ibid., 71.

83 Ibid., 193.
} 
chaos to order"—-followed by his interaction with his creations, and his ultimate decision to "free" them. ${ }^{84}$

To consider this narrative self-awareness only as a rhetorical strategy, as previous critics have done, is to obscure its dependence on images. As already noted, the novel presents varied powers of visual marking: some harmful (as in the perpetuation of false history through education and visual symbolism), some random (like the writing of an innocuous phrase, "Goodbye Blue Monday," on the side of a highly destructive bomb), and some beneficial though easily corrupted (like Trout's inability to share the purpose of life thanks to his inability to mark a wall). There is another widely recognized power in marking, though, which is the expression of identity. In her reminiscences about her father's legacy, Nanette Vonnegut recalls most of all his markings left on the walls of their home, and his father's markings throughout his childhood home—phrases painted above the mantelpiece, murals in the stairwell, a monogrammed "V"-all in the same distinctive script which Nanette remembers copying as she wrote "Shit, Fuckitty Shit" on her own bedroom wall. ${ }^{85}$ These memories recall, above all, the visual style of each Vonnegut generation, and the distinct sense of identity their markings leave behind. Peter Reed similarly recalls the author's tendency as he moved toward the graphic arts to use his hastily-drawn selfportrait - like the one on the final page of Breakfast of Champions — as a signature. The inclusion of hand-drawn doodles in his novel then should signal a conscious attempt at authenticity through marking, and an awareness of the distinct identity it leaves behind.

As previously discussed, William Blake's move toward composite publications similarly hinged on the expression of artistic individuality. Faced with a cultural pessimism

\footnotetext{
${ }^{84}$ Ibid., 210, 294.

${ }^{85}$ Vonnegut, Drawings, 8.
} 
toward visualizing the abstract, he admitted the possible corruption through printing.

Nevertheless, with full awareness of its complications, Blake chose to embrace the power of words and images to create multidisciplinary works that only he could produce, and which therefore bore witness to the authenticity of his creative action. Vonnegut's production, in the same vein of self-criticism, hides behind its critical tone while using the power of wordimage duality to make what is perhaps the densest example of self-expression of his career. In the cases of both Blake and Vonnegut, one sees two possible ways of reading their attempts to create individuality.

The first is in the context of self-criticism and self-parody. Despite his triumphant embrace of verbal and visual media, some of Blake's manuscripts betray a persistent selfdoubt. Mitchell points to the figure of Urizen, depicted on the title page to The Book of Urizen with a strained brow, a quill in each hand, and a hunched back over an enormous book, as a possible figure of Blake himself. ${ }^{86}$ Though a typical reading of this image is associated with Blake's mockery of his contemporaries, Mitchell posits a different interpretation:

But suppose we were to look at this image as a self-portrait of the artist as a solitary reader and writer of texts, a figure of the textual solipsist who insists on doing everything at once-writing his poems with one hand, for instance, while he illustrates them with the other? Or reading the classics and writing commentaries at the same time? Suppose we were to see this, in other words, as a self-parody in which Blake has a bit of fun at his own expense, expressing in a pictorial joke what he cannot quite bring himself to say in print $?^{87}$

This interpretation suggests a more fatalistic view of composite works in that their supreme individuality must be paid for with self-obsession or by selling the soul to both media. In other words, rather than triumphing over the corruption of publishing, Blake might be seen as

\footnotetext{
${ }^{86}$ Mitchell, Picture Theory, 123.

87 Ibid., 123.
} 
losing himself to it completely. In any case, his illuminated manuscripts at least acknowledge such artistic failure as a nightmarish possibility.

Given the undertone of contradiction and fallibility in Breakfast's word-image demonstrations, a similarly pessimistic reading of Vonnegut's composite work is understandable. Addressing the issue of comic persona, Charles Berryman delivers an exceptionally clear picture of Breakfast as an exercise in self-critique. The version of the self-aware Vonnegut that Berryman describes is of "a naïve character, bewildered and lost in his own novel" as he comically tries to understand the nature of his own art. ${ }^{88}$ The implication here is that Vonnegut's sense of creative control through text and illustration comes with a presupposition of failure; the real message of the novel is then a satire of creative power in general. Referencing the narrator's self-assigned role as a Creator, Berryman concludes, "If the chief delusion of an author is the attempt to assume divine creative power, Vonnegut deliberately mocks his comic persona for indulging in such pretensions. ${ }^{89}$ In this light, the self-portrait with which Vonnegut concludes his novel speaks to the same doubt and mockery that Mitchell ascribes to Blake's Urizen. He offers an abstract yet haggard profile of the author with an enormous nose, a severe brow, and a giant tear leaking from the eye. Following the conclusion of the textual narrative, in which the narrator "frees" Kilgore Trout and dematerializes, ignoring Trout's crying pleas, a likeness of the author's distraught face seems to admit failure. If Peter Reed is correct in equating selfportrait with signature, Vonnegut signs off Breakfast of Champions with a mocking jab at his own failure as a complete creator.

\footnotetext{
${ }^{88}$ Berryman, “Comic Persona," 162.

89 Ibid., 168.
} 
Those critics who denounced the novel as "hypocritical manure" might agree with such a reading, though it gives Vonnegut more credit than perhaps they would like. Despite its pessimism, the conclusion that Breakfast is at its core an exercise in willing failure is certainly supported by the novel's fusion of text and imagery, but still reinforces Vonnegut's complexity as an author. However, there is also an optimistic reading that has been readily applied to the composite works of Blake, but has not yet been extended to Vonnegut: that is, despite the fallibility of his chosen media, and despite the irony of attempting creative authenticity, the production of a truly composite work nevertheless achieves a level of individualized expression rarely seen in literary or visual art alone.

In the history of literary criticism, Blake has certainly been allowed this overarching triumph. Taking on the broader effects of Blake's composite art, Mitchell notes the extent to which all of Blake's poetic illuminations, regardless of their self-critical content, are ultimately reaffirming of the individual and of personal artistic vision. He reminds us,

All art, of course, even that which claims only to provide a mirror image of external reality, transforms its subject matter in some way, through the imposition of some style or convention. But the very subject matter of Blake's art is this power to transform and reshape visual imagery, and, by implication, the ability of man to create his vision in general. ${ }^{90}$

Blake's triumph, then, as a multidisciplinary artist is not to depict doubly nature in words and images, but to depict singularly his unique vision, which is comprised of both entities in unification. The power of totally individualized production lies in the very ability to produce, rather than in the veracity of the production. In reference to Blake's pictorial style, which is significantly more detailed than Vonnegut's doodling, Mitchell contends that Blake

\footnotetext{
90 Mitchell, Blake's Composite Art, 37.
} 
"demonstrates that the appearances of nature are to some extent ... arbitrary, and subject to transformation by the imagination of the artist." ${ }^{" 91}$

These observations extend quite naturally to Breakfast of Champions, in which themes of over-simplified representation — or complete misrepresentation — are nevertheless indicative of Vonnegut's power to manipulate each representation as he pleases. Whereas a traditional text relies on the reader to formulate his or her own mental imagery, Vonnegut steps in to take over that role. Whatever image comes to an individual reader's mind at the word "beaver," Vonnegut replaces it with his unique visual interpretation. Or, whatever narrative comes to mind when shown a sketch of an American flag, Vonnegut replaces with his own version of U.S. history. Beneath all of the tangled social critique, the real subject of this novel is Vonnegut himself. One critic, Robert Merrill, began to tap into this function of the novel (which he calls "a bildungsroman about a fifty-year-old artless artist"92) when he suggested, "In a very real sense, then, the novel dramatizes its author's internal debate."93 Vonnegut may fail as "Creator of the Universe," but by engaging with—and, more importantly, unifying — both visual and textual representation of earthly "reality," Vonnegut triumphs in reproducing his own vision.

Of course, in the vein of self-parody, there is some doubt as to whether or not the vision expressed in Breakfast of Champions is Vonnegut's own, or just a satirical version given to his fictional narrator, Philboyd Studge. This distinction will forever be speculative. However, as a work of composite art, this novel empowers the author to express whatever self he chooses, whether it be authentic or not. As Mitchell summarizes, the "essential unity" of composite works "lies in the convergence of each art form upon the goal of affirming the

\footnotetext{
91 Ibid.

92 Merrill, “Heliogabalus," 153.

${ }^{93}$ Ibid.,, 155.
} 
centrality of the human form (as consciousness or imagination in poetry, as body in the paintings) in the structure of reality." 94 The literary artwork of William Blake, then, is "an art of 'Living Form,' built upon the stylistic interplay between linear abstraction and concrete representation, ... working to find the form and meaning of the moment, the individual life, and the total expanse of human history." 95

In weighing Breakfast of Champions against these definitions ascribed to Blake, the novel proves as much of a composite work as any. Despite tension between cooperation and contradiction, word and image in this novel point continuously back to a narrative voice, a narrative consciousness, and its power to shape creative content. For a novel that fixates on the haplessness of artistic agency, Breakfast demonstrates extreme capability on Vonnegut's part to transmit his ideas and his individuality as an artist. In critically approaching this peculiar novel, it is therefore only fitting to momentarily suspend debates about Vonnegut's personal philosophies, his judgment of his own abilities, or his critique of postmodern societies, and recognize the sophistication and supremacy of his expression of the artistic self.

\footnotetext{
${ }^{94}$ Mitchell, Blake's Composite Art, 38.

${ }^{95} \mathrm{Ibid}$.
} 


\section{Conclusion}

When William Blake introduced the notion of composite publishing, he irrevocably redefined the boundaries of both literary and visual creativity. To this day, his achievement as a multidisciplinary artist and as the father of single-handed multimedia publishing is unmatched. His philosophies on artistic production are by no means the only authority on multimedia publication, nor are the works exhaustive in their demonstration of its possibilities. However, as the first mature explorer of a unified word-image dynamic in creative publication, Blake is an invaluable resource when considering the composite works of others.

Breakfast of Champions has been long overlooked in its capacity as a composite work. The majority of its scholarly criticism has delved bravely into the complexities of Vonnegut's narrative voice, prose style, and exploration of the self, but in doing so they have routinely ignored the novel as a truly multimedia work. Rather than an esoteric text peppered with insulting illustrations, Breakfast is a mature postmodern demonstration of the kind of composite practice that originated with William Blake. I do not mean to suggest any sense of lineage between Blake's illuminated manuscripts and Vonnegut's novel, nor to suppose that Vonnegut's multimedia attempt makes any conscious reference to Blake's legacy. I do, however, contend that the fullest interpretation of Breakfast of Champions may only be reached by considering the novel in the terms of a composite work.

Beneath the sarcasm and irreverence, the presence of images in Vonnegut's novel symbolically activates a critique of visual culture in lived experience that a descriptive text alone could not. Vonnegut chooses not only to analyze the powers and fallibilities of visual recognition in life on Earth, but to consciously participate in the process itself. Breakfast of 
Champions is not a collection of passive observations as it pretends to be, but rather a living example of its own critique. It is self-referential to the highest degree. It provides a direct engagement with the artistic consciousness and must therefore speak with both of its languages: word and image.

Of course, in the vein of postmodern literature, the narrative of Breakfast hinges on themes of disunity, alienation, and lack of control. Its fictional characters live insignificant lives plagued by randomness, at the mercy of a disillusioned narrator; those critics who have defined the novel in terms of Vonnegut's creative self-doubt are right to do so. But to trust Vonnegut's tipped hand and ignore the greater complexity and sophistication that is clearly at work in this novel would be a mistake. Despite its overt claims on disenchantment and creative failure, Breakfast of Champions is paradoxically an act of artistic unity. An unfinished act, perhaps, but nevertheless a great stride in the direction of creative wholeness. As such, this deceiving novel has earned a higher place in the Vonnegut canon and a more appropriate consideration in the history of multimedia publication. 
Bibliography

Allen, William Rodney. Understanding Kurt Vonnegut. Columbia, University of South Carolina Press, 1991.

Berryman, Charles. "Vonnegut's Comic Persona in Breakfast of Champions." In Critical Essays on Kurt Vonnegut, edited by Robert Merrill, 161-170. Boston: G. K. Hall and Co., 1990.

Blunt, Anthony. The Art of William Blake. New York: Columbia University Press, 1959.

Eaves, Morris. William Blake's Theory of Art. Princeton: Princeton University Press, 1982.

Klinkowitz, Jerome. Kurt Vonnegut. New York: Methuen, 1982.

Merrill, Robert. "Vonnegut's Breakfast of Champions: The Conversion of Heliogabalus." In Critical Essays on Kurt Vonnegut, edited by Robert Merrill, 153-161. Boston: G. K. Hall and Co., 1990.

Messent, Peter B. "Breakfast of Champions: The Direction of Kurt Vonnegut's Fiction." Journal of American Studies 8 (1974): 101-114.

Mitchell, W. J. T. Blake's Composite Art: A Study of the Illuminated Poetry. Princeton: Princeton University Press, 1978.

Mitchell, W. J. T. Picture Theory. Chicago: Chicago University Press, 1994.

Myrone, Martin. The Blake Book. London: Tate Publishing, 2007.

Paley, Morton D. William Blake. Oxford: Phaidon Press, 1978.

Prescott, Peter S. "Nothing Sacred [Review of Breakfast of Champions]." In Critical Essays on Kurt Vonnegut, edited by Robert Merrill, 39-40. Boston: G. K. Hall and Co., 1990.

Rodriguez, Diana. "The Absurdity of Suicide: The Existential Struggle Explored by Vonnegut in Breakfast of Champions." New Academia: An International Journal of English Language Literature and Literary Theory 2, no. 4 (2013): 1-4.

Viscomi, Joseph. Blake and the Idea of the Book. Princeton: Princeton University Press, 1993.

Vonnegut, Kurt. Breakfast of Champions, or Goodbye Blue Monday. New York: Dell Publishing, 1973. 
Vonnegut, Kurt, Nanette Vonnegut, and Peter J. Reed. Kurt Vonnegut Drawings. New York: Monacelli Press, 2014.

Vonnegut, Kurt, and William Rodney Allen. Conversations with Kurt Vonnegut. Jackson: University of Mississippi Press, 1988. 